\title{
RELATION BETWEEN CAROTID ISCHEMIC EVENTS AND LEGNTH OF INTERNAL CAROTID STENOSIS
}

Ahmed M. Elhfnawy ${ }^{1}$; Jens Volkmann, MD; $\mathrm{PhD}^{1}$; Mirko Pham, MD ${ }^{2}$; and Felix Fluri, MD ${ }^{1}$

\author{
${ }^{1}$ Department of Neurology, University Hospital Würzburg, Würzburg, Germany
}

${ }^{2}$ Department of Diagnostic and Interventional Neuroradiology, University Hospital of Würzburg, Würzburg, Germany

\section{Introduction}

High-grade internal carotid stenosis (ICS) $>70 \%$ is a leading cause of ischemic stroke. ${ }^{1}$ However, a considerable percentage of stroke survivors with a symptomatic ICS have $<70 \%$ stenosis. 2,3 Different characteristics such as fibrous plaques or thin ruptured cap or ultrasonographically echolucent plaque have been identified as markers for high risk plaques. ${ }^{4}$ Whether the length of the ICS is also associated with a high risk of ischemic stroke has never been investigated.

\section{Methods}

In a carotid disease register based approach, 208 ICS in 168 patients with stroke or transient ischemic attack were identified. The degree of ICS was measured by ultrasound, the length by ultrasound, MR-angiography and/or DSA. Plaque echogenicity was classified into predominantly hypoechogenic, mixed or predominately echogenic category.

\section{Results:}

A statistically significant inverse relationship between the length and degree of ICS was detected for the internal carotid artery of the symptomatic $(\rho=-0.33, p<0.001)$ but not of the asymptomatic side $(\rho=0.06, p=0.65)$. The median (IQR) length for $<70 \%$ symptomatic ICS was $18(\mathbf{1 4 . 8 8 - 2 1 . 0 0 )} \mathbf{m m}$, whereas for $\geq 70 \%$ symptomatic ICS was $16(12-20) \mathrm{mm}(p=0.047)$. A cut-off length for ICS of $\geq 14.46 \mathbf{m m}$ was found to have a sensitivity and specificity of $78 \%$ and $48 \%$, respectively for differentiating between symptomatic and asymptomatic stenosis. ICS of the symptomatic side were significantly more echolucent compared to the ICS of the asymptomatic side (44\% vs $27 \%$, $\boldsymbol{p}=\mathbf{0 . 0 2}$ ). This relation was even more evident among $<70 \%$ ICS (symptomatic versus asymptomatic; echolucent plaques $46.7 \%$ versus $24.5 \%$, echogenic $35.6 \%$ versus $67.9 \%$; $p=0.006$ ).

\section{Conclusion:}

Stroke occurrence in patients with ICA-stenosis $<70 \%$ might be - to some extent - related to plaque length and plaque echolucency. Patients with ICS $<70 \%$ of $\geq 14.88 \mathrm{~mm}$ length, especially if the plaque is echolucent should be considered as high risk patients and might profit from frequent follow-up examinations or even carotid revascularization procedures.

Table 1: Different plaque characteristics among symptomatic and asymptomatic internal carotid stenosis. IQR, interquartile range.

\begin{tabular}{|c|c|c|c|}
\hline & $\begin{array}{c}\text { Symptomatic } \\
\text { side (n=133) }\end{array}$ & $\begin{array}{c}\text { Asymptomatic } \\
\text { side }(\mathbf{n}=67)^{*}\end{array}$ & p-value \\
\hline $\begin{array}{c}\text { Plaque echolucency, } \mathbf{n}(\%) \\
\text { Hypoechoic }\end{array}$ & $55(44 \%)$ & $17(27 \%)$ & $0.02+$ \\
mixed & $17(13.6 \%)$ & $5(7.9 \%)$ & $0.34+$ \\
Echogenic & $53(42.4 \%)$ & $41(65.1 \%)$ & $0.03+$ \\
\hline $\begin{array}{c}\text { Severity of stenosis, } \mathbf{n}(\%) \\
<70 \%, n(\%)\end{array}$ & $46(35.1 \%)$ & $56(88.9 \%)$ & $<0.001$ \\
$\geq 70 \%, n(\%)$ & $85(64.9 \%)$ & $7(11.1 \%)$ & \\
\hline $\begin{array}{l}\text { Plaque length in duplex in } \\
\text { mm, median (IQR) }\end{array}$ & & & \\
All carotid arteries & $17.0(12.0-20.51)$ & $16.0(12.0-$ & 0.40 \\
$<70 \%$ ICA stenosis & $18.0(14.88-21.0)$ & $19.25)$ & 0.08 \\
$\geq 70 \%$ ICA-stenosis & $16.0(12-20)$ & $15.5(12.0-19.0)$ & 0.64 \\
& & $18.0(11-20)$ & \\
\hline
\end{tabular}

${ }^{*}$ In 8 patients the stenosis could not be classified, + statistical analysis for a difference between the mentioned type versus both other types

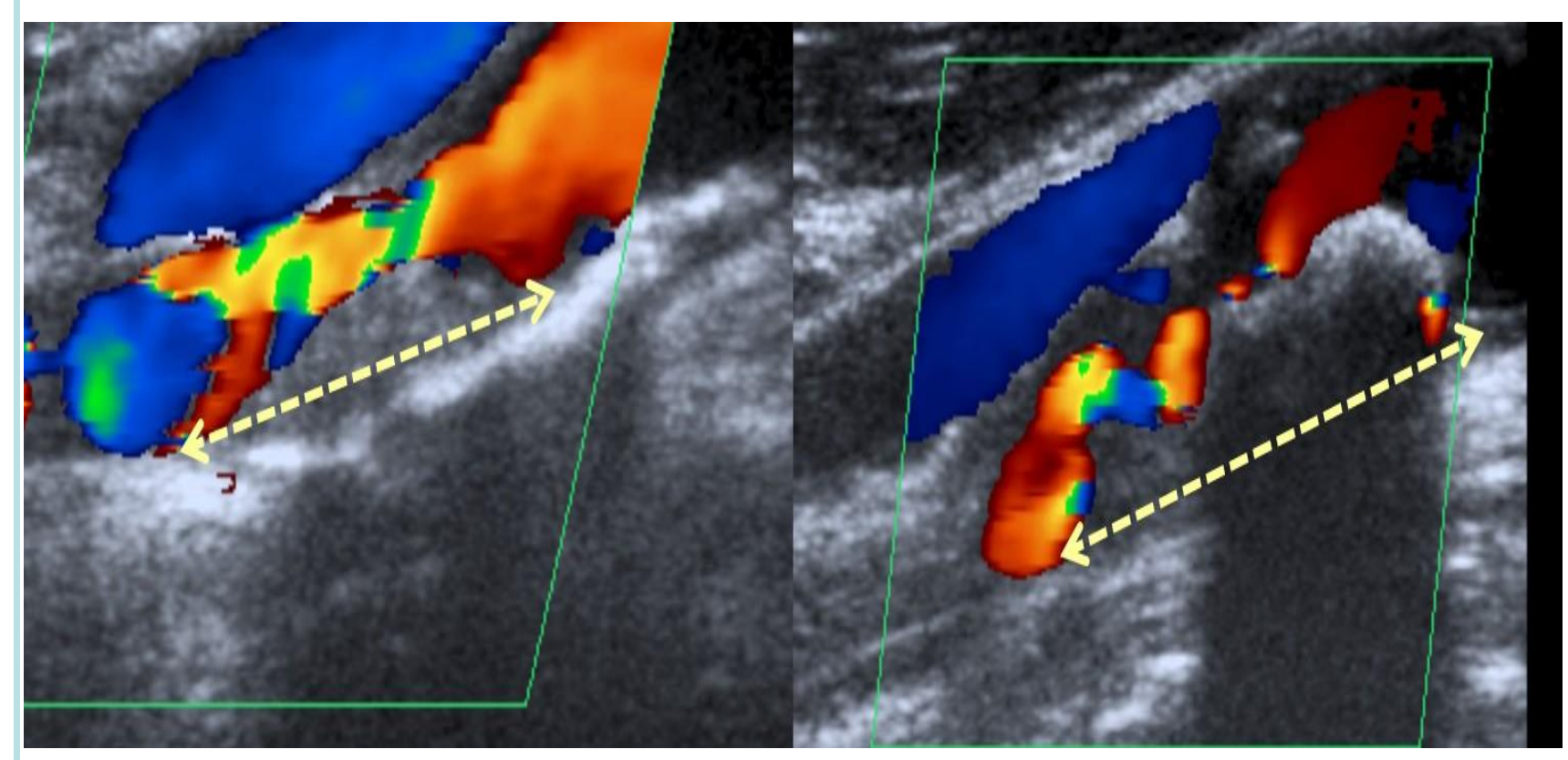

Figure 1: Assessment of length of internal carotid artery stenosis. Representative example of a duplex scan (B-mode). The length of stenosis was measured from the most proximal to the most distal stenotic area (indicated by a dashed line)

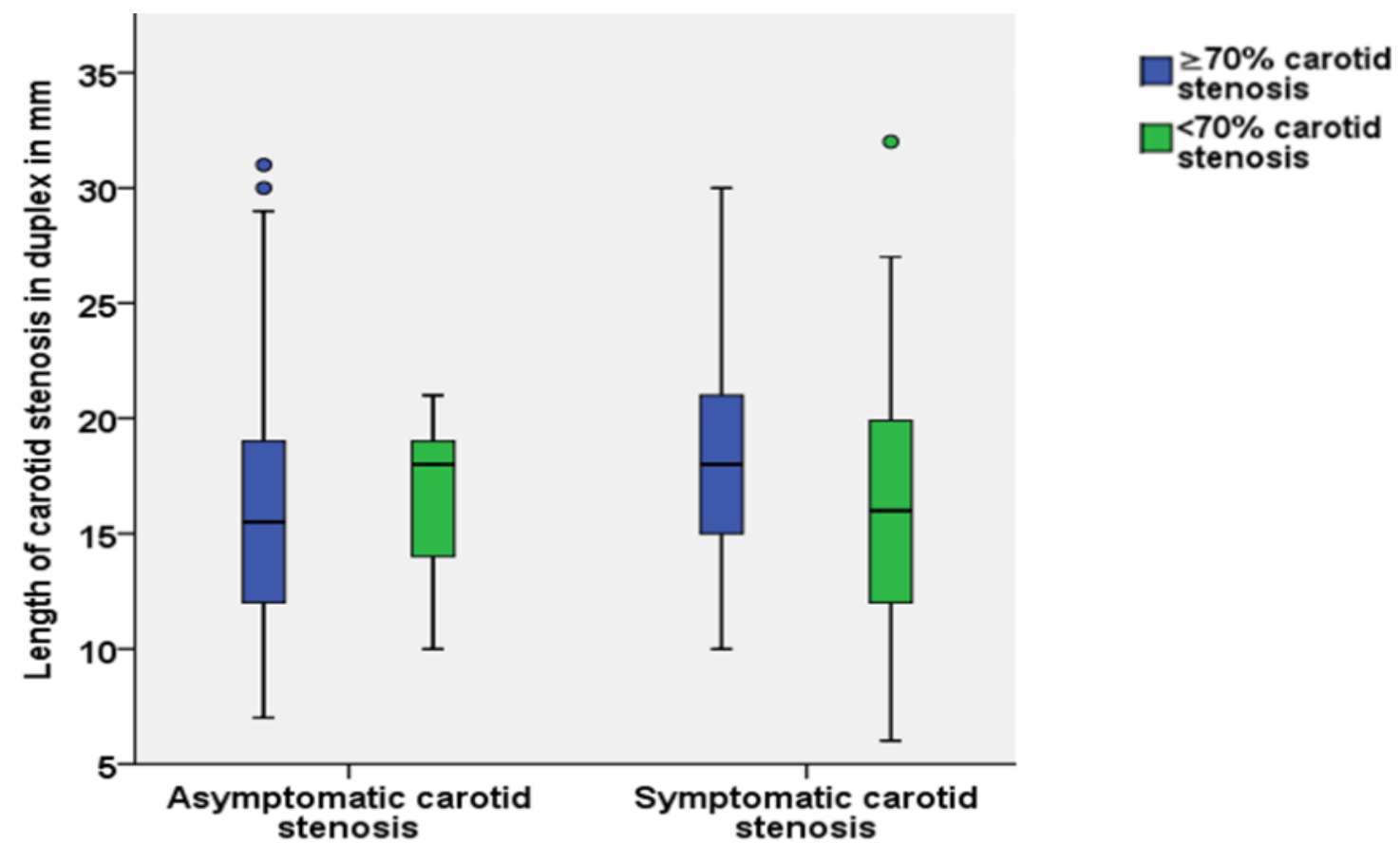

Figure 2: Relation between the length of internal carotid artery stenosis among symptomatic and asymptomatic arteries in patients with $<70 \%$ versus $\geq 70 \%$ ICS.
1. Lovett JK, Coull AJ, Rothwell PM. Early risk of recurrence by subtype of ischemic stroke in population-based incidence studies. Neurology 2004;62:569-573. 2. Yamada K, Kawasaki M, Yoshimura S, Sasaki Y, Nakahara S, Sato Y. Asymptomatic moderate carotid artery stenosis with intraplaque hemorrhage: onset of new ischemic stroke. $J$ Neurolnterventional Surg 2016;8:130-134.

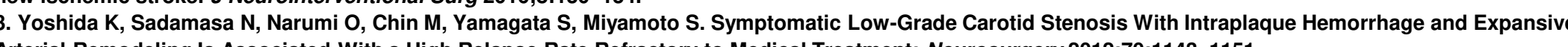
(1) Stroke 2013;44:3071-3077.
Copyright @ 2017 Elhfnawy AM, Volkmann J, Pham M, Fluri F Department of Neurology, University Hospital Würzburg, JosefSchneider Strasse 11, 97080 Würzburg, Germany Phone: +49-931-201-34350; fax: +49-931-201-23488 ; E-mail: Ahmedmelhfnawy@gmx.de 